\title{
MODELO DE PROPENSÃO A OCUPAÇÕES IRREGULARES EM LINHAS DE TRANSMISSÃO DE ENERGIA ELÉTRICA
}

\author{
Julia Cucco* \\ Francisco Henrique de Oliveira**
}

\begin{abstract}
RESUMO:
O sistema de transmissão de energia elétrica demanda restrições quanto a utilização de suas áreas adjacentes devido a alta-tensão dos cabos de energia. Apesar das restrições serem instituídas por lei, há um crescente número de ocupações irregulares nestas áreas. Considerando a finalidade de monitoramento e gestão nas faixas de servidão - áreas adjacentes à linha de transmissão - os recursos geotecnológicos são fontes eficiente de reconhecimento físico territorial e de apoio à decisão visando a ocupação segura e legal. O estudo apresentado auxilia na detecção das invasões já ocorridas em um trecho de transmissão localizado no Estado de Santa Catarina, gerenciado pela Eletrosul Centrais Elétricas, e indica por meio de um princípio metodológico, as áreas que atraem novas invasões. A atratividade foi gerada a partir do estabelecimento de pesos para as quatro variáveis consideradas determinantes para ocupação, a citar a)Uso e ocupação do solo, b) Proximidade das vias, c) Declividade e d) Distanciamento das torres. O produto final caracterizou o mapeamento de propensão à invasão que possibilita desenvolver ações preventivas pela concessionária Eletrosul e que se intensificam nos locais da faixa de servidão apontados com alta propensão à invasão.
\end{abstract}

PALAVRAS-CHAVE: Faixas de servidão; Linhas de Transmissão; Ocupação irregular; Sistemas de Informações Geográficas

\section{ABSTRACT:}

Power Line Transmissions Systems demand restrictions on the use of its adjacent areas due to it's high voltage power cables. Despite the fact that many restrictions are imposed by law, there is a growing number of illegal occupation in those areas. Having in mind the purposes of monitoring and management of Transmission line corridors - adjacent areas to the transmission lines - georesources are efficient sources of territorial management and support to take decisions about a safe and lawful occupation. The present study helps to detect irregular occupations that have been occurring in a section of a transmission line located in Santa Catarina State. The corridor area, focus of this research managed by Eletrosul, is used here as a reference for a suggested principle of methodology in areas that attract new invasions. The appeal of that area was generated from the establishment of weights to the four variables considered crucial for occupation, as follow a) land use, b) neighborhood road, c) slope and d) proximity between towers. The final product is a map of propensity of invasion and allows preventive actions by Eletrosul, as well as to identify the local Transmission line corridor appointed with high propensity for invasion.

KEY-WORDS: Transmission line corridor, Power Line Transmission, Illegal occupation, Geographic Information Systems

* Universidade Federal de Santa Catarina. email: juliacucco@yahoo.com.b

** Universidade do Estado de Santa Catarina. email: chicoliver@yahoo.com.br 


\section{Introdução.}

Atualmente a valorização de espaços territoriais tem ganhado força, motivada pela demanda de habitação. Devido a isso, a procura por locais adequados para instalações com fins de moradia em algumas cidades no país apresenta-se como árdua e onerosa tarefa para as secretarias de planejamento.

A falta de controle e de uma gestão efetiva, pautada em cartografia adequada, com profissionais preparados, favorece a ocorrência de edificações em locais impróprios e que por isso, podem muitas vezes resultar em danos tanto para a sociedade - que se utiliza do espaço irregular quanto para o meio ambiente, que sofre com ações antrópicas em áreas sensíveis.

O poder público municipal, por meio de suas atribuições, deve fazer uso do Estatuto das Cidades (Lei 10.257) e desenvolver um Plano Diretor adequado ao seu município, que regulamente a utilização do território e seus arredores evitando ocupações em potenciais áreas de risco.

Os sistemas de infraestrutura energética, como reservatórios e gasodutos exigem restrições quanto ao tipo de utilização em seus arredores, devido a alta-tensão dos cabos, segundo preconiza o Ministério de Minas e Energia em 1997, no documento intitulado Sistema de Gestão Sócio Patrimonial.

Neste contexto, o sistema de transmissão de energia elétrica brasileiro, constituído por diferentes concessionárias, representa uma grandiosa rede interligada que segundo dados da ANEEL (2008), somam 90 mil quilômetros de extensão linear.

O espaço ocupado pelas torres e o entorno por elas também ocupado deve ser respeitado frente à diversas formas de ocupação. Esta determinação é estabelecida pela Associação Brasileira de Normas Técnicas (ABNT), que define para Projetos de Linhas Aéreas de Transmissão de Energia Elétrica a NBR 5422 - contendo os parâmetros para o cálculo da largura da área a ser mantida livre de ocupações. Esta área protegida é chamada Faixa de Servidão.

As concessionárias, em conjunto com o Ministério de Minas e Energia, de acordo com o descrito na NBR 5422, definiram os espaçamentos necessários para compor a faixa de servidão para cada tensão de Linha; quanto maior a tensão, maior a área restritiva.

A Figura 1 representa as distâncias mínimas que devem ser respeitadas para fins de faixa de servidão.

Figura 1- Ilustração das tensões e suas respectivas distâncias destinadas à faixa de servidão.

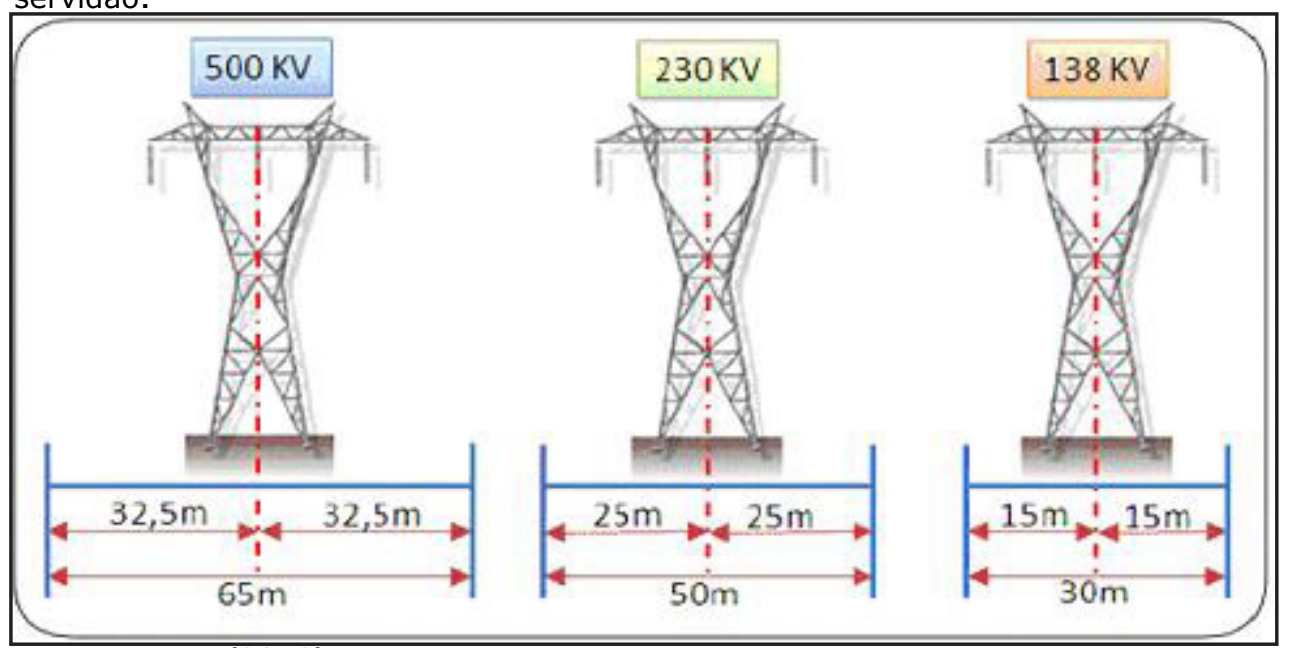

Fonte: Wosny, (2010) 
A faixa de servidão é internacionalmente instituída. As linhas de transmissão de outros países possuem as chamadas right of ways, com espaçamentos entre 80 e 140 pés (corredores de 24 a 42 metros), segundo Public Service Commission of Wisconsin, [2005] conforme ilustra a Figura 2.

Figura 2 - Ilustração de distâncias de faixa de servidão para Linhas de Transmissão estrangeiras.

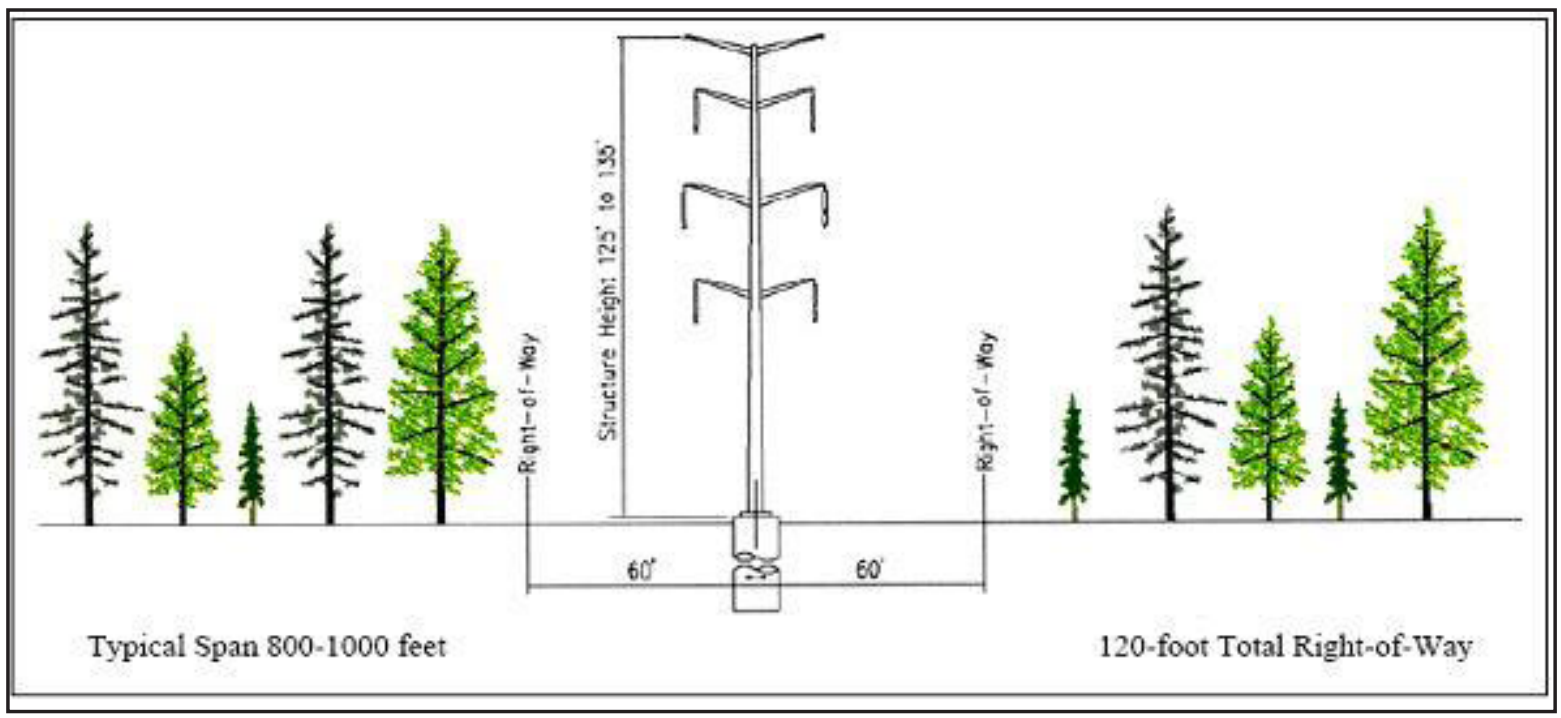

Fonte: PUBLIC SERVICE COMMISSION OF WISCONSIN, [2005]

Independente da tensão das Linhas, e conseqüentemente da distância da faixa de servidão, as restrições brasileiras impostas são iguais e estão, de forma simplificada, apresentadas no Quadro 1.

Ouadro 1 - Restriç̃̃es de utilização na faixa de servidão.

\begin{tabular}{|c|c|}
\hline \multicolumn{2}{|c|}{ Utilizações proibidas na faixa de servidão } \\
\hline Âmbito Rural & $\begin{array}{c}\text { Benfeitorias associadas às atividades } \\
\text { pecuárias e agricolas; Instalações } \\
\text { elétricas e mecânicas; Açudes. }\end{array}$ \\
\hline Âmbito Urbano & $\begin{array}{c}\text { Edificações; Loteamentos; Praças e } \\
\text { parques; Paradas para ônibus; Âreas } \\
\text { industriais e comerciais; } \\
\text { Estacionamentos. }\end{array}$ \\
\hline Sistema de Infraestrutura & $\begin{array}{c}\text { Ruas; Redes de água e esgoto; Rede de } \\
\text { comunicação. }\end{array}$ \\
\hline Atividades Extrativas & $\begin{array}{c}\text { Exploração de jazidas; serviços de } \\
\text { terraplenagem. }\end{array}$ \\
\hline
\end{tabular}

Fonte: BRASIL (1997) 
Apesar das restrições impostas, e da faixa de servidão ser instituída por lei, as concessionárias responsáveis pelas Linhas de Transmissão identificam um crescente número de ocupações irregulares nestas áreas, que se tornam recorrentes, uma vez que a fiscalização, dada a extensão das Linhas, é ineficiente para acompanhar a dinâmica da ocupação.

Para finalidade de monitoramento os recursos geotecnológicos apresentam-se como recurso hábil e confiável visando a determinação das ocupações irregulares em faixas de servidão, tomando como referência as imagens de satélite de alta resolução espacial e de softwares especializados em SIG - Sistemas de Informações Geográficas. (OLIVEIRA, WOSNY e SANTO, 2006)

Os dados obtidos através do mapeamento das ocupações no ambiente SIG possibilitam conhecer os locais mais acometidos pela ocupação irregular, e frente a isto, identificar as características em comum dos locais invadidos.

A partir da identificação das invasões, o diagnóstico auxilia na definição das variáveis que ao serem analisadas através da atribuição de pesos em modelagens matemáticas, resultam em um modelo preditivo sobre os locais mais propensos à invasão.

As variáveis relacionadas à propensão que compuseram o modelo preditivo partiram das seguintes análises temáticas:

a) Legislação urbana de ocupação do solo - pelo tipo de utilização em áreas de faixa de servidão e em suas proximidades;

b) Infraestrutura - pela proximidade da faixa de servidão às vias de acesso;

c) Aspectos geomorfológicos - através da análise de relevo da faixa de servidão; e

d) Localização das torres - pela não regularidade de distância entre as torres, possibilitando ocupação da faixa de servidão nos maiores vazios formado entre elas.

\section{Diagnóstico da ocupação das Linhas de Transmissão e entorno}

Com intuito de corroborar a escolha das variáveis a serem utilizadas para formular o estudo, trechos de faixa de servidão foram analisados aleatoriamente para diferentes estados brasileiros.

Através de imagens de satélite de alta resolução, analisaram-se trechos do estado do Rio de Janeiro, Santa Catarina e São Paulo no intuito de apresentar a real situação da faixa de servidão evidenciando ocupações irregulares quando existentes.

Os três trechos, localizados em áreas urbanas e administrados por diferentes concessionárias serviram de teste, dado que o arranjo da situação de cada faixa de servidão e seus arredores poderia prever se haveria ou não a ocorrência de invasão.

Para o trecho localizado no Rio de Janeiro a ocupação em grande parte da faixa de servidão se mostra inexistente, conforme ilustra a Figura 3. A isto, pode-se atribuir o cercamento feito através de muros, de modo a conter o estabelecimento de residências ou ainda ruas, ou qualquer outro tipo de utilização indevida na faixa de servidão. Esta medida pode ser uma atuação efetiva da concessionária responsável pelo trecho ou também resultado da conscientização da população dos perigos da Linha de Transmissão.

Para o trecho apresentado no Estado de São Paulo, é notório o avanço de construções na faixa determinada para fins de servidão, assim como no trecho de estudo em Santa Catarina. Nas duas situações não há indícios de contenção por cercamento de muros, e a grande concentração de casas e vias muito próximas explica a ocorrência de invasão. A Figura 4 (A e B) identifica dois casos, uma para cada trecho. 
Modelo de propensão a ocupações

irregulares em linhas de transmissão de energia elétrica. pp. 107 - 120.

Figura 3 - Trecho de Linha de transmissão Estado do Rio de Janeiro. Fonte: Autores, (2011).

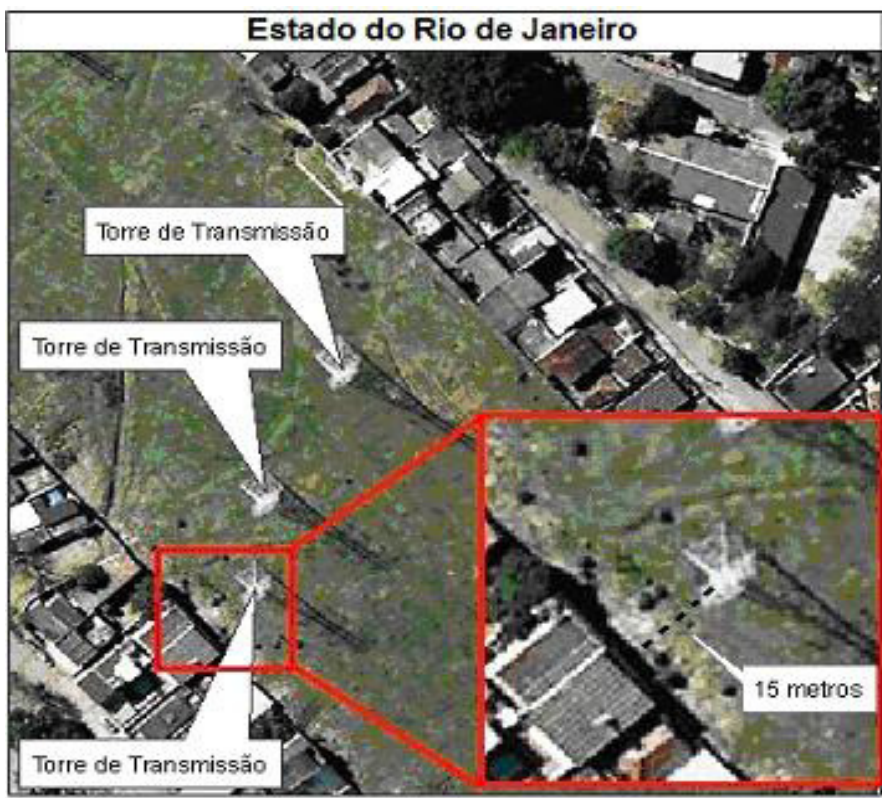

Figura 4 - Dois trechos (A e B) de Linha de Transmissão São Paulo e Santa Catarina respectivamente. Fonte: Autores, (2011).

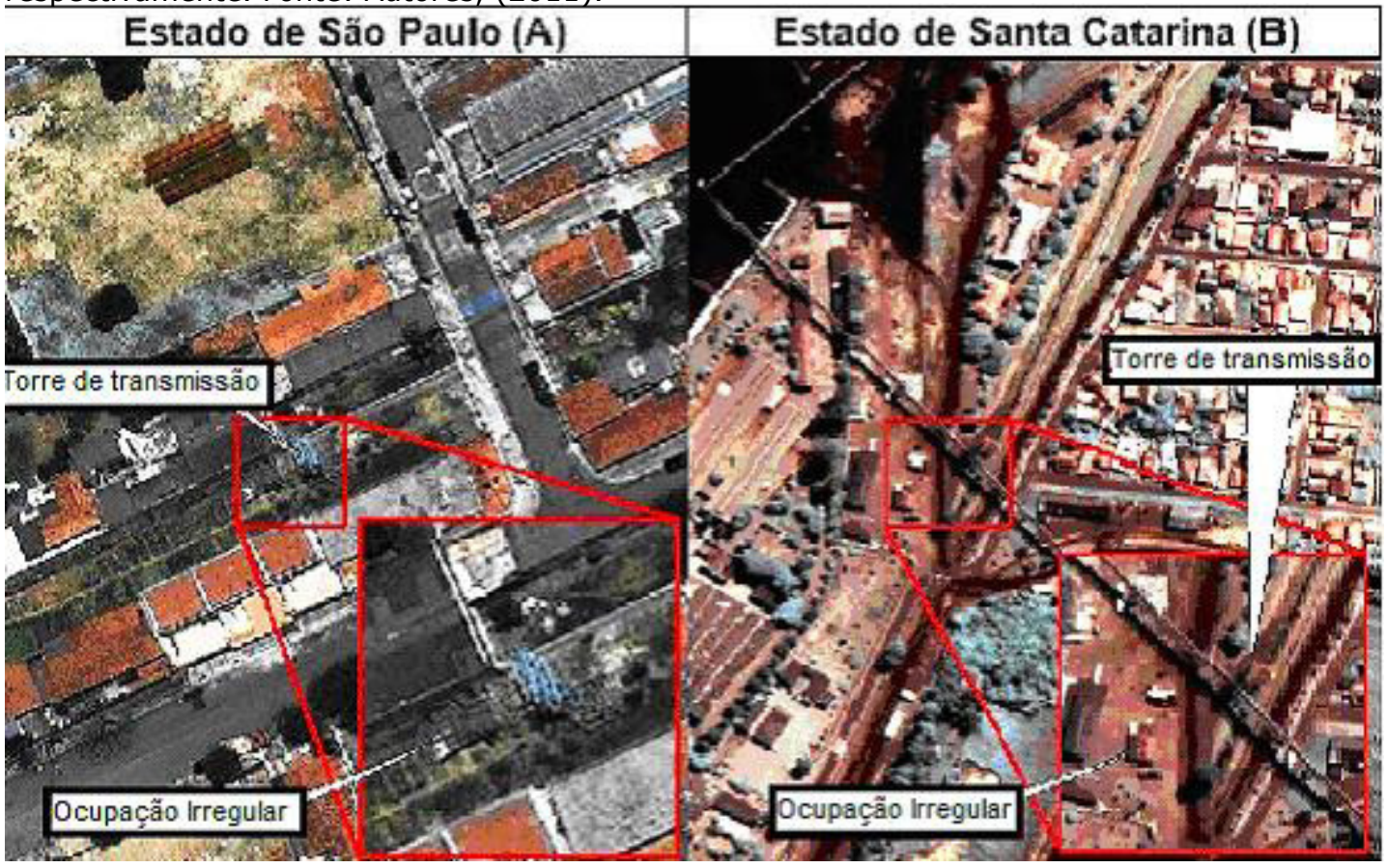


Para análise e aplicação do método, o trecho de estudo apresentado na Figura 4B, gerenciado pela Eletrosul Centrais Elétricas S/A com $110 \mathrm{Km}$ de extensão de Linha de Transmissão, foi escolhido.

O estudo no território Catarinense iniciou na termelétrica Jorge Lacerda, no município de Capivari de Baixo, e finalizou na subestação de energia elétrica, no município de Palhoça. A tensão desta Linha de Transmissão corresponde a $138 \mathrm{kV}$, e por isso exige uma faixa de servidão com 15 metros paralelo ao sentido da linha para cada um dos lados.

Para definir a área de faixa de servidão sobre as imagens de alta resolução Quickbird mapeou-se inicialmente as torres do trecho de estudo. Através da localização obtida por meio de levantamento com GPS, as torres eram encontradas e marcadas em feição de ponto no ambiente SIG, o banco de dados do software ArcGIS 9.2, recebia e armazenava as informações provenientes do mapeamento.

Um arquivo disponibilizado pela concessionária contendo o número total de torres e a distância entre elas auxiliou na determinação das torres e agregou informações ao banco de dados.

A precisão da localização, desta forma, esteve vinculada ao georreferenciamento das imagens utilizadas no mapeamento, por sua vez subsidiado pela coleta de coordenadas acuradas de pontos de controle com GPS Geodésico para verificação e confrontação da qualidade geométrica do procedimento.

Com a definição das torres, a faixa de servidão foi projetada para ambos os lados das torres em 15 metros, delineada com auxílio da ferramenta Buffer, que projeta um espaçamento a partir de um eixo central, tal qual a linha de transmissão.

Esta etapa foi essencial para definir o espaçamento que caracteriza a faixa de servidão, uma vez que as edificações inseridas sobre esta área foram consideradas irregulares e por isso deve ser removida para atender as normas de segurança.

No mesmo ambiente SIG, com a determinação da faixa de servidão, partiu-se por representar as feições que caracterizavam as invasões através da geração de polígonos, em escala de visualização de 1:2.500.

As invasões representadas no trecho de estudo e no seu entorno - uma área 85 metros além da faixa de servidão - foram mapeadas com objetivo de melhor subsidiar as análises acerca do modelo de propensão.

Através deste mapeamento, com imagens coletadas no ano de 2004, foram localizadas 2.798 edificações para a faixa de servidão e sua área adjacente. O Quadro 2 abaixo apresenta o número de edificações detectadas para cada município, além da respectiva área em $\mathrm{Km}^{2}$ de faixa de servidão e da área ocupada irregularmente.

O município com maior incidência de edificações para a faixa de servidão, Palhoça, é também o mais populoso e mais desenvolvido dentre os demais municípios do trecho segundo dados coletados do Instituto Brasileiro de Geografia e Estatística - IBGE, o que explica em partes o destaque resultante do estudo.

\section{Modelo preditivo a ocupação irregular em faixas de servidão}

A primeira etapa - identificação de invasões - foi de fundamental importância e antecedeu o mapeamento das variáveis que compuseram o modelo de propensão.

Além das variáveis definidas para mapeamento: a) Uso e ocupação do solo; b) Proximidade das vias; c) Declividade do terreno; e d) Distanciamento das torres, foi de suma importância determinar como seria classificada a propensão à invasão para cada uma das variáveis.

A metodologia aplicada - apresentada também por Araújo e Kux (2005) para determinar a propensão através de pesos atribuídos conforme a importância no mapeamento - foi definida como adequada frente à proposta do estudo, 
com diferentes variáveis e níveis graduais para propensão a invasão.

Para determinar o grau de atratividade geraram-se pesos dentre as classes das variáveis, de modo que determinada característica correspondia a um nível de propensão.

Os pesos atribuídos valeram-se de valores numéricos, onde o peso 1 caracterizou Baixa Propensão, 2 Baixa-média Propensão, 3
Média Propensão, 4 Média-alta Propensão e 5 Alta Propensão, constando, portanto 5 níveis gradativos. A classificação apresentada se baseou conforme a teoria de Saaty (1977) descrita por Louzada et al. (2009) que indica valores hierárquicos a serem atribuídos relacionados a variáveis lingüísticas de importância. À medida que as imagens foram interpretadas, as feições foram inseridas no banco de dados do software, conforme ilustra a Figura 5.

\begin{tabular}{|c|c|}
\hline \multicolumn{2}{|c|}{ Utilizações proibidas na faixa de servidão } \\
\hline Âmbito Rural & $\begin{array}{l}\text { Benfeitorias associadas às atividades } \\
\text { pecuárias e agrícolas; Instalações } \\
\text { elétricas e mecânicas; Açudes. }\end{array}$ \\
\hline Âmbito Urbano & $\begin{array}{c}\text { Edificações; Loteamentos; Praças e } \\
\text { parques; Paradas para ônibus; Arreas } \\
\text { industriais e comerciais; } \\
\text { Estacionamentos. }\end{array}$ \\
\hline Sistema de Infraestrutura & $\begin{array}{c}\text { Ruas; Redes de água e esgoto; Rede de } \\
\text { comunicação. }\end{array}$ \\
\hline Atividades Extrativas & $\begin{array}{c}\text { Exploração de jazidas; serviços de } \\
\text { terraplenagem. }\end{array}$ \\
\hline
\end{tabular}

Quadro 2 - Quantitativo de edificações, área de faixa de servidão, chamada também de faixa de segurança e área de ocupação irregular por município

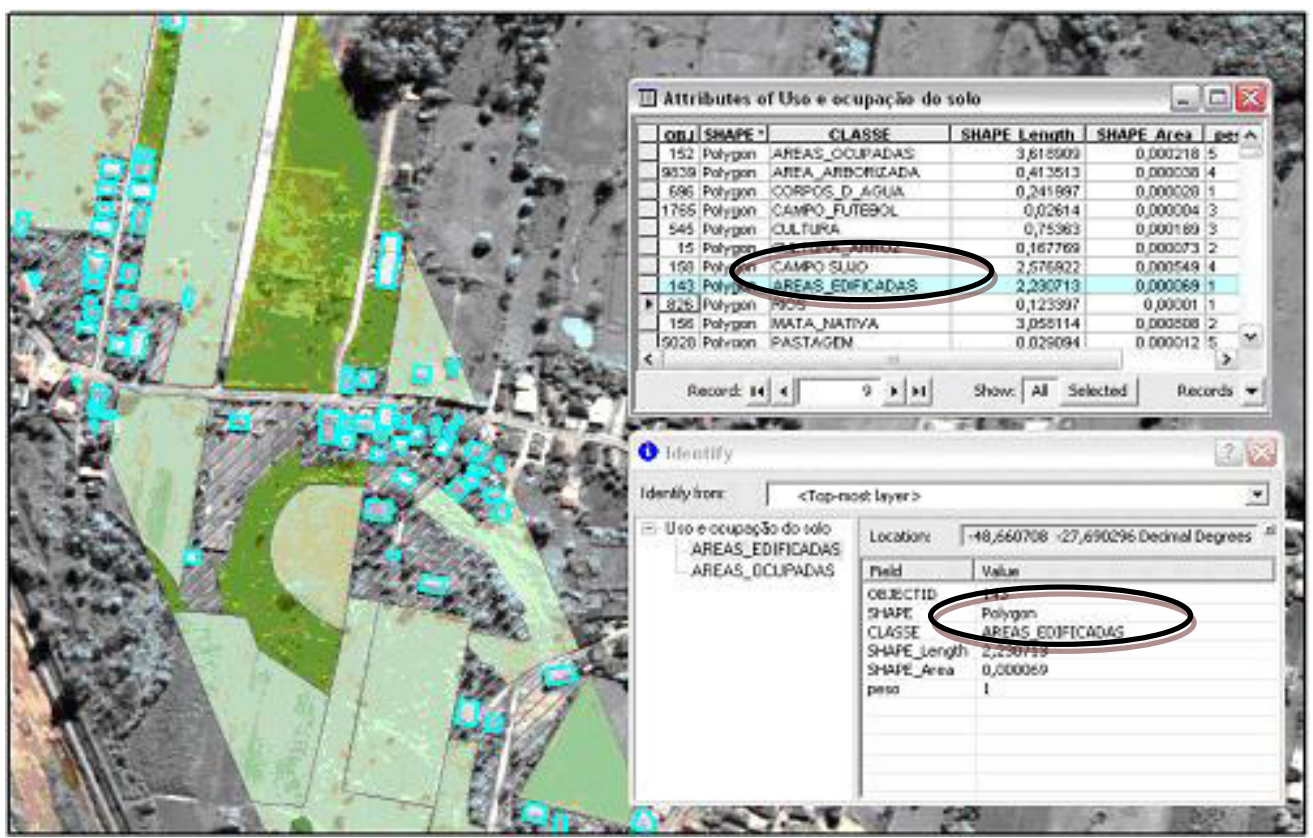

Fonte: Autores, (2011). 
Cada classe no momento da interpretação e da classificação no banco de dados recebeu um peso que caracterizou empiricamente a atratividade que representou a ocupação.
A variável Uso e ocupação do solo foi interpretada como feição gráfica em forma de polígono, as classes utilizadas para esta variável seguem descritas no Quadro 3 com os respectivos pesos aplicados.

Quadro 3 - Classes e respectivos pesos para a variável "A" - Uso e ocupação do solo.

\begin{tabular}{|c|c|c|}
\hline $\begin{array}{c}\text { Classes de Uso e Ocupação } \\
\text { do Solo }\end{array}$ & $\begin{array}{c}\text { Peso } \\
\text { atribuido }\end{array}$ & Mapeamento \\
\hline Áreas ocupadas & 5 \\
\hline Pastagens & 5 \\
\hline Solos expostos & 4 \\
\hline Áreas arborizadas & 4 \\
\hline Campos sujos & 3 \\
\hline Campo de Futebol & 3 \\
\hline Cultura & 3 \\
\hline Silvicultura & 2 \\
\hline Rizicultura & 2 \\
\hline Mata nativa & 1 \\
\hline Áreas edificadas & 1 \\
\hline Hidrografia & \\
\hline Vias e canteiros & \\
\hline
\end{tabular}

As classes de menor peso foram consideradas pela sua difícil ou quase nula propensão à ocupação, pois se partiu do pressuposto de que nas áreas já edificadas, ou com vias e canteiros, a ocupação física da área já está estabelecida, e para as áreas com rios e cursos d'água, a chance de ocupação seria possível se estas áreas fossem aterradas.

É importante distinguir a classe "área ocupada", que representa as áreas cercadas ou ainda que fazem parte de um lote, mas que não está edificada, apenas delimitado. É por este motivo que quando mapeadas, essas situações receberam maior peso, valor 5 . 
Para a classe Proximidade das vias, a atratividade para novas invasões foi mensurada pela localização do sistema viário em relação à área de estudo. As vias foram mapeadas durante a vetorização do Uso e Ocupação do Solo, e foram exportadas para um arquivo separado.

Para definir a propensão em relação à proximidade das vias, os pesos foram gerados através de espaçamentos de 25 metros em relação a via principal, de modo a compreender a largura do trecho.

Para cada espaçamento de 25 metros um peso foi atribuído, e desta forma, o espaçamento mais próximo às vias ganhou maior peso, em relação ao último espaçamento, que distou 125 metros da via principal e recebeu peso mínimo. 0 Quadro 4 representa os pesos utilizados.

Quadro 4 - Classes e respectivos pesos para a variável "B" - Proximidade das vias.

\begin{tabular}{|c|c|c|}
\hline $\begin{array}{c}\text { Classes de Proximidade das } \\
\text { vias }\end{array}$ & $\begin{array}{c}\text { Peso } \\
\text { atribuido }\end{array}$ \\
\hline 0 a 25 metros & 5 \\
\hline 25 a 50 metros & 4 \\
\hline 50 a 75 metros & 3 \\
\hline 75 a 100 metros & 2 \\
\hline 100 a 125 metros & 1 \\
\hline
\end{tabular}

Para inferir a propensão de ocupação através do relevo, gerou-se, através de curvas de nível, o modelo de elevação para a área de estudo.

As gradações de relevo basearamse na resolução do CONAMA (Conselho Nacional de Meio Ambiente), lei número 4771/85 que em seus artigos destacam as inclinações de áreas que devem ser preservadas, e na lei do Parcelamento do Solo, lei número $6766 / 79$, que não permite que sejam parcelados os terrenos com determinada declividade.

Estas especificações auxiliaram na composição dos valores e conseqüentemente dos pesos atribuídos, que seguem descritos no Quadro 5. 


\begin{tabular}{|c|c|c|}
\hline Classes de Declividade & $\begin{array}{c}\text { Peso } \\
\text { Atribuido }\end{array}$ & Mapeamento \\
\hline 0 a $3 \%$ & 5 & \\
\hline 3 a $8 \%$ & 4 & \\
\hline 8 a $20 \%$ & 3 & \\
\hline 20 a $45 \%$ & 2 & \\
\hline Acima de $45 \%$ & 1 & \\
\hline
\end{tabular}

Para definir a variável de Distanciamento das torres, utilizou-se espaçamentos em função do eixo de cada torre, como feito para determinar os pesos de propensão para a variável de Proximidade das vias.

Os espaçamentos pré-determinados de 15 metros em torno de todas as torres geraram as gradações. Quanto menor o espaçamento entre as torres, menor foi o peso atribuído, conforme apresenta o Quadro 6.

Com a geração dos arquivos componentes do modelo de propensão, a preocupação foi adaptá-los ao formato de cruzamento de dados, uma vez que o modelo se caracteriza pela operação matemática entre as variáveis e seus pesos.

Todos os arquivos contendo as classes e seus respectivos pesos foram convertidos para o formato Raster ${ }^{1}$, onde o valor de cada pixel foi correspondente ao peso atribuído à feição.

A proposta de cruzar os dados através de operações matemáticas permitiu agregar as variáveis em um só resultado, gerando valores obtidos da união da propensão que cada fator, representado pelas variáveis.
Para dar destaque a cada variável separadamente no modelo, foram estipulados valores no momento dos cálculos para representar a atratividade individual de cada variável.

O princípio da soma de variáveis com graus de importância diferentes, possibilitada via software, visa obter um mapa temático que apresente visualmente a sobreposição de informações subjetivas, resultando em níveis graduais para entendimento da realidade. Elliot e Wadley (2002) utilizam-se deste mesmo princípio para determinar o impacto gerado no valor de propriedades urbanas e rurais com a instalação de trechos de transmissão relacionando diferentes variáveis subjetivas.

O modelo proposto de sobreposição das variáveis considerando individualmente seu grau de importância resultou na expressão apresentada abaixo:

[(uso do solo $* 0,5)+$ (distância das vias $* 0,25)+($ declividade $* 0,125)+$ (proximidade das torres $* 0,125$ )]

A expressão foi aplicada na extensão spatial analyst do software utilizado no mapeamento. O cálculo, conforme apresentado, considerou a variável de uso e ocupação do solo 
com $50 \%$ de importância para a geração do modelo de propensão à invasão, seguido da variável distância das vias, com $25 \%$. As duas outras variáveis receberam ambas, $12,5 \%$ de influência.
O modelo de propensão, resultante da sobreposição das variáveis, obtido pela expressão descrita, segue ilustrado na Figura 6.

Quadro 6 - Classes e respectivos pesos para a variável - Distanciamento das torres.

\begin{tabular}{|c|c|c|}
\hline $\begin{array}{c}\text { Classes de Distanciamento das } \\
\text { torres }\end{array}$ & $\begin{array}{c}\text { Peso } \\
\text { Atribuido }\end{array}$ & Mapeamento \\
\hline $60-85$ metros & 5 & \\
\hline $45-60$ metros & 3 \\
\hline $30-45$ metros & 2 \\
\hline $15-30$ metros & 1 \\
\hline $0-15$ metros & \\
\hline
\end{tabular}

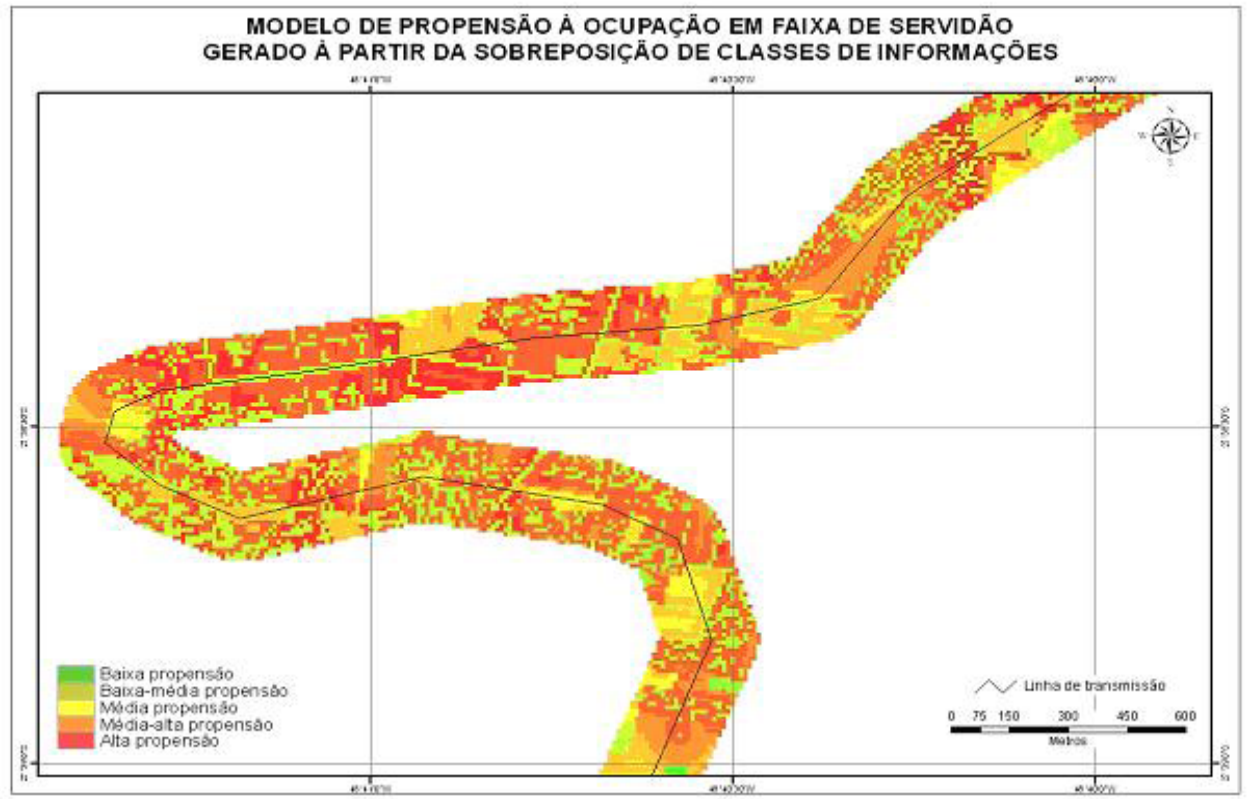

Figura 6 - Modelo gráfico de propensão à invasão. Fonte: Autores (2011) 


\section{Resultados e Discussão}

A inicial identificação da situação de invasão para o trecho de estudo Capivari de Baixo - Palhoça forneceu o quantitativo de ocupações irregulares a partir da interpretação sobre imagens de alta resolução.
O modelo de propensão gerado pela soma das variáveis possibilitou determinar as áreas com maior atratividade à ocupação.

As áreas com alta propensão à ocupação totalizaram $8 \%$, os demais quantitativos seguem representados na Figura 7.

Figura 7 - Representação do quantitativo em percentagem de propensão para o trecho de estudo. Fonte: Autores, 2011.

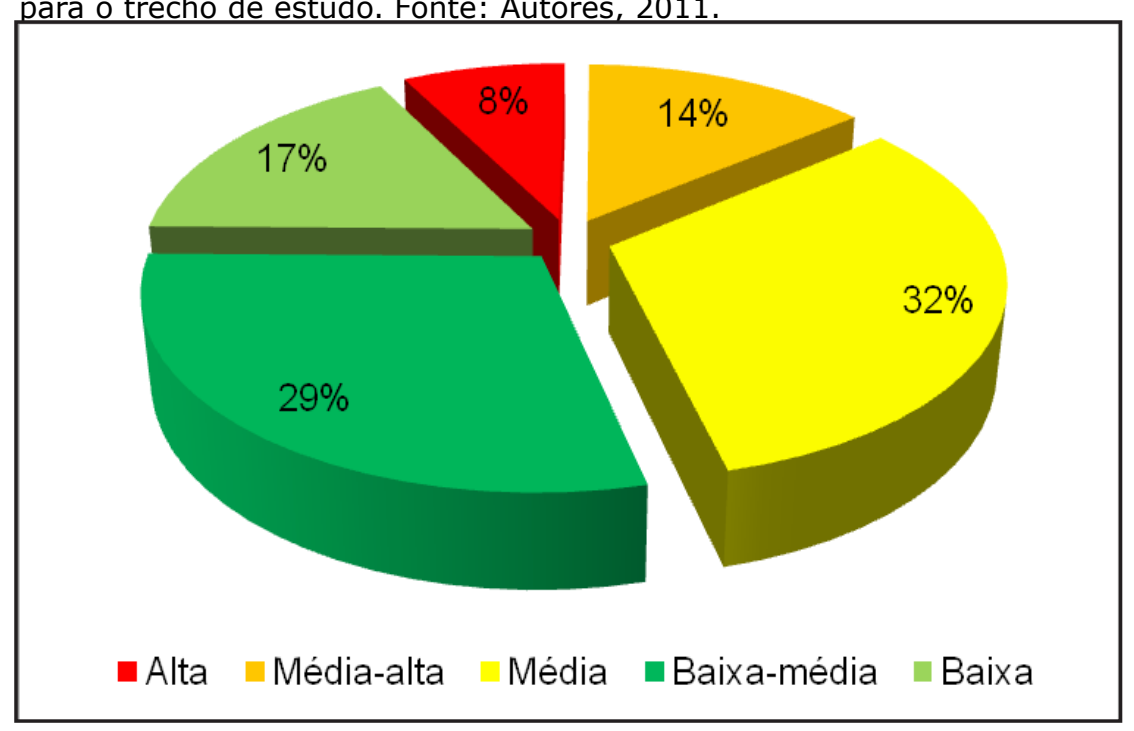

Com a indicação em percentuais de potencial à invasão na faixa de servidão, destacamse os locais que se encontram em situação delicada, onde deve haver maior atenção com intuito preventivo.

Neste sentido, medidas cabíveis e dentro do princípio do planejamento territorial partiriam da integração entre concessionárias e prefeituras para que, frente ao problema de invasão, se unissem objetivando gerar um Plano Diretor dialogado, considerando em especial a gestão da faixa de servidão.

É incompreensível que sistemas grandiosos e de importância para sociedade quanto o de energia elétrica fiquem vulneráveis à falta de planejamento e integração de informações que prejudicam sua segurança, premissa mister da faixa de servidão.
O conhecimento das áreas mais propensas a ocupação irregular apresentado pelo estudo executado é de fundamental importância para prefeitura, uma vez que pode atuar preventivamente nestas localidades e defini-las como áreas com restrições de utilizações.

Esta medida visa revisar as áreas aptas ao parcelamento do solo de cada município, para que quando próximo aos corredores de transmissão, seja impossibilitada qualquer utilização para fins de moradia, comércio e lazer principalmente, mantendo a prefeitura em conformidade as normas de segurança.

Estas áreas, em vez de serem encaradas como ônus territorial pela prefeitura, podem fazer parte de projetos municipais de caráter comunitário em parceria com a concessionária 
responsável.

Nesta situação, hortas comunitárias podem ser aceitas na faixa de servidão mediante a apresentação de projetos, desde que sejam de baixo porte arbustivo e não demande sistemas mecânicos e de irrigação para plantio.

Atendendo estas especificações é possível conter em partes as invasões e tornar a população aliada, conscientizando-a dos riscos e da ilegalidade de se ocupar essas áreas para fins de moradia.

\section{Considerações Finais}

A proposta de modelo de propensão desenvolvida em ambiente SIG, através das variáveis e seus pesos, apresentou-se como ferramenta indispensável à gestão do setor elétrico para a questão de segurança, em especial à situação da população frente aos riscos implícitos na rede de tensão.

O modelo de propensão a ocupações irregulares permite que as ações preventivas adotadas pela concessionária responsável pelo trecho se intensifiquem nos locais da faixa de servidão apontados com alta propensão à invasão.
As diversas possibilidades exemplificadas direcionam pontualmente a equipe da concessionária à situação, resultando em agilidade no processo de regularização da faixa de servidão.

É importante salientar que a base do modelo se sustenta na interpretação das imagens de satélite, que devem ser recentes para garantir resultados atuais. Desta forma, para que haja manutenção do modelo, é necessário investir em imagens periodicamente dada a dinâmica com que se caracterizam as ocupações.

Com a realidade das invasões caracterizada nos produtos cartográficos gerados nas etapas de desenvolvimento, sobretudo no modelo de propensão, têm-se subsídio suficiente para regularizar a faixa de servidão conforme prescreve a legislação.

É possibilitado ainda, através do mapeamento da área adjacente à faixa de servidão, reconhecer locais que possam absorver a demanda das ocupações irregulares, ou seja, aplicar de fato a teoria do planejamento e gestão a essa área de responsabilidade das empresas de transmissão de energia elétrica.

\section{Notas}

1. A representação raster trata o espaço mapeado como uma superfície plana dividida em células com determinada informação associada. (LUCHIARI;KAWAKUBO; MORATO, 2005), 2005)

\section{Bibliografia}

ANEEL, Agência Nacional de Energia Elétrica (Brasil). Atlas de energia elétrica do Brasil. 3. ed. Brasília: Aneel, 2008. 236 p.

ARAÚJO, E. H. G.; KUX, H. J. H. Identificação de áreas com propensão à edificação no bairro Belvedere em Belo Horizonte utilizando sensoriamento remoto e técnicas de geoprocesamento. Anais XII Simpósio Brasileiro de Sensoriamento Remoto, Goiânia, Brasil, 1621 abril 2005, INPE, p. 3461-3468. Disponível em: <http://marte.dpi.inpe.br/col/ltid.inpe.br/ sbsr/2004/11.12.14.12/doc/3461.pdf >. Acesso em: 17 jan. 2011.

BRASIL. Ministério das Cidades. Déficit
Habitacional no Brasil: Municípios Selecionados e Microrregiões Geográficas. Brasília: Fundação João Pinheiro, 2006. 111 p.

BRASIL. Ministério das Minas e Energia. Sistema de Gestão Sócio-Patrimonial: Setor Elétrico. São Paulo, 1997. 77 p.

COMISSÃO NACIONAL DE CARTOGRAFIA. Infraestrutura Nacional de Dados Espaciais: Especificação Técnica para a Estruturação de Dados Geoespaciais Vetoriais. Brasília: Diretoria de Serviço Geográfico, 2008.

ELLIOTT, P.; WADLEY, D. The Impact of Transmission Lines on Property Values: Coming to Terms with 
Stigma. Property Management. EUA. p. 137152, 2002.

INSTITUTO BRASILEIRO DE GEOGRAFIA E ESTATÍSTICA (IBGE). Canais - Cidades. Disponível em: <http://www.ibge.gov.br/ cidadesat/topwindow.htm?1>. Acesso em 10 dez. 2011.

LOUZADA, F. L. R. O.; PIROVANI D. B.; LOUGON, M. S.; SANTOS, A. R. dos Análise De Vulnerabilidade Do Parque Estadual Cachoeira Da Fumaça, ES. In: Encontro Latino Americano de Iniciação Científica, 13., 2009, Anais... [S.N.] 2009. CDROM.

LUCHIARI, A.; KAWAKUBO, F. S.; MORATO, R. G. Aplicações do Sensoriamento Remoto na Geografia. In: VENTURI, L. A. B. Praticando Geografia: Técnicas de campo e laboratório. São Paulo: Oficina de Texto, 2005. p. 33-54.

OLIVEIRA, F. H.; WOSNY, G. C.; SANTO, M. A. D.
Sistema de Informação Geográfica apoiando o Mapeamento temático e o Cadastro das Linhas de Transmissão de Energia Elétrica. Florianópolis. 2006. 13 p.

PINHEIRO, E. S.; KUX, H. J. H. Imagens Quickbird Aplicadas ao Mapeamento de Uso e Cobertura da Terra do Centro de Pesquisas e Conservação da Natureza Pró-Mata. São Paulo. 2004. 21p.

PUBLIC SERVICE COMMISSION OF WISCONSIN. (EUA). Electricity: From Power Plants to Consumers, [2005]. Wisconsin, $13 \mathrm{p}$.

RAMOS, C. S. Visualização Cartográfica e Cartografia multimídia: Conceitos e Tecnologias. 2005. ed. São Paulo: Unesp, 2005. 178 p.

WOSNY, G. C. Proposta de Base Cartográfica para Linhas de Transmissão de Energia Elétrica. 2010. 188 f. Dissertação (Mestre) - Universidade Federal de Santa Catarina, Florianópolis, 2010. CD-ROM. 